\title{
NEW PHYSIOLOGICAL LABORATORY AT OXFORD
}

A NEW Physiological Laboratory has been built in Oxford, at a cost of $£ 300,000$, and is now coming into use. It has been designed by Prof. F. G. T. Liddell, Waynflete professor of physiology in the University, in consultation with the architects, Messrs. Lanchester and Lodge.

The old laboratory was begun in 1883 and cost $£ 10,000$. In those days the annual intake of students was small-seven in 1887. In 1908 a new block for physiological chemistry was added, at a cost of $£ 5,500$. The building could then accommodate an optimum number of twenty-five students a year, and in 1914 the number was twenty-six. Severe strain was first felt in the wake of the First World War : the 1923 class numbered 63. In 1926 things were made easier by the foundation of the Department of Biochemistry, in that bench space for the whole of 'chemical physiology' was no longer needed in the old laboratory. But student numbers never fell to the pre-War level: the number of class-meetings attended by each student had to be cut down, classes had to be duplicated, and the need for a new laboratory became every year more urgent. The late Prof. John Mellanby planned a $\$ 102,000$ building in the late 1930's, but this had to be given up in 1939 . The newly built Laboratory will bring relief to students and teachers alike, for the 1952-53 class numbered 79, exceeding by threefold the capacity of the old classrooms.

The new building is of stone-coloured brick. It has four stories, three staircases and goods and passenger lifts. It is long and narrow, $360 \mathrm{ft}$. long and $75 \mathrm{ft}$. wide at its centre. This shape, imposed by the shape of the only available site, gives a spurious impression of vastness which can only be corrected by viewing it end-on. It provides bench space for an annual intake of a hundred students. Research accommodation is also increased, but not in proportion to the increased room for teaching.

The main entrance hall and large lecture theatre together fill a large part of the centre of the building, and are two stories high. The lecture theatre seats 250 , in fourteen parallel, steeply sloped tiers. At the back are external projection and rewinding chambers, and beneath these a glass-fronted gallery whence late-comers may see what goes on within, and whence they may unobtrusively enter. For demonstrations there is an oval well-shaped theatre with leaningspace for a hundred spectators. Also on the ground floor are two classrooms for muscle-nerve experiments; a darkened classroom for ophthalmic work ; the main engineering shop ; and four research rooms (one of them screened from electrical interference), with their photographic dark-rooms and office and workshop accommodation.

On the first floor are the professor's offices, and two research rooms, with dark rooms, for himself and his associates. Human physiology has two classrooms and three research rooms, one of which incorporates a cold room. The staff common room is on this floor.

The second floor has a small lecture room seating 85 ; a large classroom for histology, and a smaller one for more advanced histological work for the senior class; classrooms for mammalian physiology and for advanced electrophysiology; the library; and

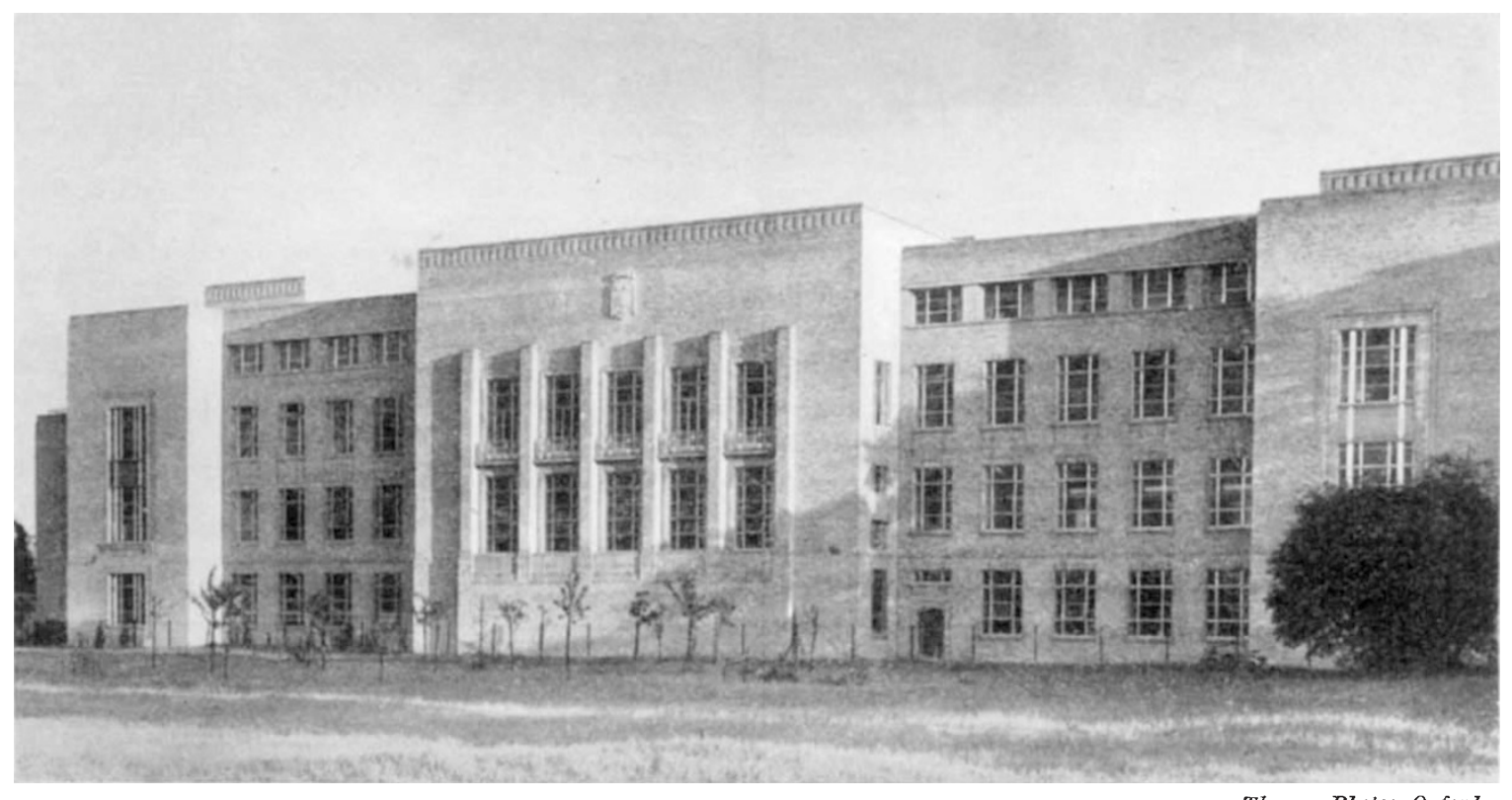

Fig. 1. Department of Physiology, University of Oxford 


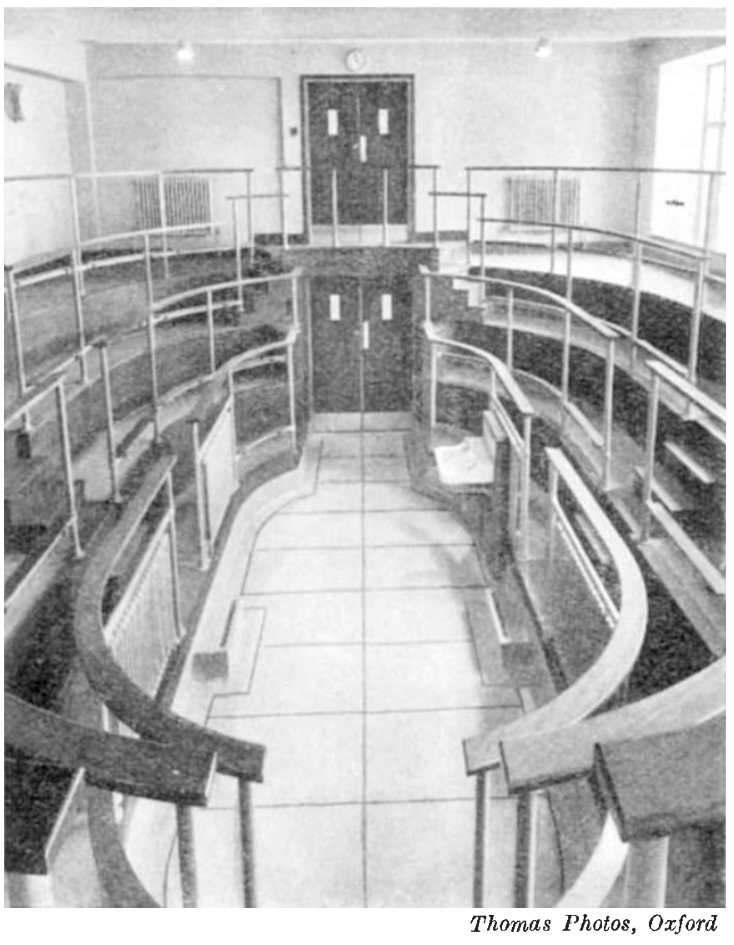

Fig. 2. Demonstration theatre

the photographic studio. Research accommodation on this floor comprises three suites of small interconnected rooms adapted to the needs of microscopical work.

The third floor opens out on to a large area of the whole length of the second-floor roof, which can be used for experimental work on muscular exercise, the subjects' courses being timed from the bay windows of a special observation room. On this floor are the operating theatre and X-ray room; an observation room for the psychological testing of small and large primates; and a spacious and well-ventilated animal house, which includes a sound-proofed dog-kennel room.

The Laboratory has been designed with the view of maximum adaptability of purpose. Rooms filled with extensive and permanent bench installations are few, and most of the classrooms and research rooms could be differently divided and furnished from time to time, as changing interests and emphasis may require.

Enough has probably been said to show that Oxford's problem of inadequate bench space for physiology has been solved. Elementary instruction will now be possible without strain ; and a start can be made with the re-expansion of the content of the courses in advanced physiology. The extent and direction of this expansion must, of course, depend on the interests of the research workers who form the teaching staff. Its pace will depend on the rate at which financial stringency will allow reinforcement of their numbers to a level which will restore the student-teacher ratios of the senior classes of former days. For there is to be no weakening of the traditional policy which strives to place before the large majority of Oxford medical students educational opportunities which are elsewhere restricted to men and women proposing to specialize in biological research.

\section{NINTH INTERNATIONAL CONGRESS OF GENETICS}

$\mathrm{T}$

HE post-war trend in international scientific meetings has been towards small symposia and conferences, and, as a consequence, there are now considerable opportunities for contact between those working within each of a number of limited fields. The main function of international congresses has become the complementary one of discussion between workers in different branches of broader fields. On this standard, the Ninth International Congress of Genetics, held this year in Bellagio during August 24-31, has been more successful than the two preceding ones (Edinburgh, 1939; Stockholm, 1948), and the organizing committee deserves the gratitude of all the members who participated.

The reasons for this success are essentially twofold. First, the number of participants-more than eight hundred-though somewhat larger than at the Eighth Congress, was still small enough for everyone to meet everyone else. With numbers exceeding, say, one thousand, personal contacts outside the sessions can only be selective and require deliberate planning. Second, the Congress was centred not on a town but on a small and quiet holiday resort. In Bellagio, members of the Congress were accommodated in hotels along a short stretch of the shore, and most of the cafés were in the same stretch : thus meeting, or looking for, any member outside session time was only a matter of walking a few yards. Unfortunately, Bellagio could not accommodate all the members: part were accommodated ten minutes away by boat across the lake, and the two groups became effectively separated in the evening.

The plenary sessions of the Congress were held in the dining-hall of a big hotel, with unsatisfactory acoustics and ventilation, and the sectional sessions were held in the classrooms of a local school, some of insufficient capacity. These shortcomings were the price to be paid for by choosing a locality without the facilities of a university, but it was well worth paying in view of the other advantages. There are two lessons which this Congress has brought home. One is that the main purpose of a congress can be achieved only if the numbers are kept well below the thousand mark. The other is that a small centre is preferable to a large town; if it could also have lecture-room facilities of university standard, then so much the better.

The work of the Congress was arranged in a novel way. The afternoons were reserved exclusively for plenary sessions, each with three or four invited papers-twenty-seven in all. During the mornings there were eight special sessions simultaneously for papers of fifteen minutes length (about three hundred in all). These special sessions were interspersed with invited lectures (fourteen in number), not overlapping with one another.

It would be impossible to give here more than an idea of trends in genetics, as detectable at the Congress.

The study of the part the genes play in the function of the cell, and secondarily in the organism, has become one of the central fields in genetics. This trend can be detected quite clearly even in indirect approaches : for example, researches on the arrangement of the genes along the chromosomes, on the induction of specific mutations, on the process of mutation itself, and even on quantitative inheritance, 